\title{
BMJ Open Effect of sex on specialty training application outcomes: a longitudinal administrative data study of UK medical graduates
}

\author{
Katherine Woolf, ${ }^{\oplus 1}$ Hirosha Jayaweera, ${ }^{1,2}$ Emily Unwin, ${ }^{1}$ Karim Keshwani, ${ }^{1,3}$ \\ Christopher Valerio, ${ }^{1,3}$ Henry Potts ${ }^{4}$
}

To cite: Woolf $\mathrm{K}$, Jayaweera $\mathrm{H}$ Unwin $\mathrm{E}$, et al. Effect of sex on specialty training application outcomes: a longitudinal administrative data study of UK medical graduates. BMJ Open 2019;9:e025004. doi:10.1136/ bmjopen-2018-025004

- Prepublication history and additional material for this paper are available online. To view these files, please visit the journal online (http://dx.doi. org/10.1136/bmjopen-2018025004).

Received 25 June 2018 Revised 4 January 2019 Accepted 7 February 2019

Check for updates

(c) Author(s) (or their employer(s)) 2019. Re-use permitted under CC BY-NC. No commercial re-use. See rights and permissions. Published by BMJ.

${ }^{1}$ Research Department of Medical Education, University College London Medical School, London, UK

${ }^{2}$ Centre for Clinical Research in Neuropsychiatry, University of Western Australia, Crawley, Western Australia, Australia ${ }^{3}$ North Middlesex University Hospital NHS Trust, London, UK ${ }^{4}$ Centre for Health Informatics and Multiprofessional Education, UCL, London, UK

Correspondence to

Dr Katherine Woolf;

k.woolf@ucl.ac.uk

\section{ABSTRACT}

Objectives To examine sex differences in the specialty training recruitment outcomes of UK medical graduates; and whether sex differences were explained by prior academic attainment and previous fitness to practise (FtP) declarations.

Design Retrospective longitudinal cohort study. Setting Administrative data on entrants to all UK medical schools from the UK Medical Education Database. Participants 10559 doctors (6 155; 58\% female) who entered a UK medical school in 2007 or 2008 and were eligible to apply for specialty training by 2015.

Primary outcome measure Odds of application, offer and acceptance to any specialty training programme, and on to each of the nine largest training programmes, adjusting for sex, other demographics, prior academic attainment, FtP declaration and medical school.

Results Across all specialties, there were no sex differences in applications for specialty training, but women had increased odds of getting an offer $(O R=1.40$; $95 \% \mathrm{Cl}=1.25$ to $1.57 ; \mathrm{p}<0.001)$ and accepting one $(\mathrm{OR}=1.43 ; 95 \% \mathrm{Cl}=1.19$ to $1.71 ; \mathrm{p}<0.001)$. Seven of the nine largest specialties showed significant sex differences in applications, which remained after adjusting for other factors. In the adjusted models, Paediatrics ( $\mathrm{OR}=1.57$; $95 \% \mathrm{Cl}=1.01$ to $2.46 ; \mathrm{p}=0.046)$ and general practice (GP) $(0 R=1.23 ; 95 \% \mathrm{Cl}=1.03$ to $1.46 ; \mathrm{p}=0.017)$ were the only specialties to show sex differences in offers, both favouring women. GP alone showed sex differences in acceptances, with women being more likely to accept $(\mathrm{OR}=1.34 ; 95 \% \mathrm{Cl}=1.03$ to $1.76 ; \mathrm{p}=0.03)$. Doctors with an FtP declaration were slightly less likely to apply to specialty training overall $(\mathrm{OR}=0.84 ; 95 \% \mathrm{Cl}=0.71$ to $1.00 ; p=0.048$ ) and less likely to accept an offer to any programme $(\mathrm{OR}=0.71 ; 95 \% \mathrm{Cl}=0.52$ to $0.98 ; \mathrm{p}=0.036)$, after adjusting for confounders.

Conclusions Sex segregation between medical specialties is due to differential application, although research is needed to understand why men are less likely to be offered a place on to GP and Paediatrics training, and if offered GP are less likely to accept.

\section{BACKGROUND}

The proportion of men and women in different medical specialties varies greatly,
Strengths and limitations of the study

- First study to assess sex differences in the likelihood of receiving and accepting an offer to UK specialty training overall and within nine specialties.

- Sex differences controlled for confounders including prior attainment.

- Large sample size and longitudinal data obtained from the UK Medical Education Database.

- Did not consider the impact of multiple applications or acceptances from multiple offers, and did not formally compare specialties.

- Large number of tests increased the likelihood of type I error.

with relatively more women in general practice (GP), paediatrics and obstetrics and gynaecology (O\&G), and more men in surgery and radiology. This so-called sex segregation is the result of preferences and constraints, themselves influenced by experiences and gendered societal norms and expectations. ${ }^{1-8}$

Less is known about whether selection processes influence sex ratios in different specialties, either directly (if the methods used to select applicants show sex differences) or indirectly (if selection methods rely on other measures such as previous academic attainment that themselves show sex differences). For example, it is known that women generally do better on Situational Judgement Tests $(\mathrm{SJTs})^{9}$ which are used in some specialty selection programmes in the UK, and they also have slightly higher medical school performance as judged by the Educational Performance Measure (EPM) used to select newly qualified doctors to UK Foundation Training. ${ }^{10}$ Understanding whether selection processes contribute to differences in the proportions of men and women in different specialties is important for effective 
workforce planning and the provision of future healthcare, and could influence efforts to reduce sex segregation in some specialties.

Relatively little published research addresses the potential influence of selection processes on outcomes. Studies and data tend to show either no sex differences, or women doing slightly better than men. In the UK, a 2013 evaluation of selection in five English regions into five specialties (core medical training, core surgical training, psychiatry, O\&G and paediatrics), found women in the sample achieved higher scores in selection into core surgical training and psychiatry after adjusting for other demographic factors, with no significant sex differences in the other specialties. ${ }^{11}$ A 2016 evaluation of GP selection found women were more likely to be successful. ${ }^{12} \mathrm{~A}$ 2017 study of selection into general and vascular surgery found no effect of sex on selection scores. ${ }^{13}$ Publicly available Canadian Resident Matching Service data from 2017 showed female Canadian medical graduates were slightly more likely to be successfully matched to a surgical specialty, with no differences in other specialties. ${ }^{14}$ Similar data for the USA are not publicly available, but an historical analysis of data from 1987 found women were more likely to get their first choice of specialty and less likely not to be matched. ${ }^{15}$ More recent studies of radiology and anaesthesia residency selection found female applicants outperformed men. ${ }^{16} 17$

Research in this area may also help us understand other areas of stark sex differences in medicine, such as disciplinary action, where male doctors have nearly 2.5 times the odds of facing medicolegal action. ${ }^{18}$ Recent research has shown male UK medical graduates have increased odds of a fitness to practise (FtP) issue at medical school, ${ }^{19}$ and professionalism problems at medical school are known to predict later sanctions. ${ }^{20-22}$ It is also known that doctors from certain specialties are at higher risk of receiving sanctions. ${ }^{23}$ It is unknown however whether graduates with an FtP declaration may favour certain specialties.

The aims of this study are:

1. To measure sex differences in specialty applications, offers and acceptances.

2. To examine whether sex differences are present in specialty applications, offers and acceptances after controlling for previous academic attainment, and other potential confounders.

3. To examine whether medical school FtP declarations predict specialty choice, taking into account sex and prior academic attainment.

\section{METHODS}

\section{Design and setting}

Longitudinal study using data from the UK Medical Education Database (UKMED). UKMED contains administrative data on UK medical students. The data and permission to use the data for research purposes was obtained from the General Medical Council (GMC). The study protocol can be found in the online supplementary material.

\section{Participants}

At the time this study was undertaken, UKMED contained data on 13763 people-5913 (43\%) men and 7850 (57\%) women-who entered medical school in 2007 and 2008. Our study population comprised 10559 doctors who entered a UK medical school in 2007 or 2008 and who had completed Foundation training and thus were eligible to apply for Specialty Training by 2015 . Compared with the full dataset, there were slightly fewer men $(n=4404 ; 42 \%)$ in this sample.

\section{Study variables}

A summary of all variables included in the analysis is given in table 1. Further details can be found in the UKMED data dictionary. ${ }^{24}$

The primary exposure of interest was a doctor's sex (male or female). The secondary exposure of interest was having a FtP declaration at application to the Foundation Programme versus having none. The primary outcomes of interest were:

- Specialty training programme(s) applied to.

- Specialty training programme offered (of those applied to).

- Specialty training programme accepted (of those offered).

- Application to a specialty training programme versus no application.

We only included first applications. We did not analyse the number of applications made, and analysed data for each specialty separately for example, if a doctor applied to two specialties, we included them in both specialties. Men and women did not differ significantly in the number of multiple applications they made $(p=0.77)$. We combined applications from all years for the analysis for everyone who entered medical school in 2007 or 2008.

Prior attainment included both medical school and pre-medical school academic attainment. Pre-medical school attainment consisted of Higher Education Statistics Agency (HESA) tariff points, which is a measure of qualifications on entry to medical school (typically A-levels), and first attempt aptitude test score, either UK Clinical Aptitude Test (UKCAT) or Graduate Medical School Admissions Test (GAMSAT). We also looked at whether or not a doctor had a university degree before entering medical school. Medical school attainment consisted of Foundation Programme Application System (FPAS) scores, available from 2012 to 2015. This included the EPM which is a quartile (2012) or decile (2013 onwards) ranking of an applicant compared with others within their medical school, SJT score (2013 onwards), degree points (awarded for university degrees other than the primary medical degree) and publication points (awarded for peer reviewed research publications). We recoded degree points into a three level variable $(0=$ no additional degrees; $1=$ additional undergraduate degree third class, lower 
Table 1 Description of variables

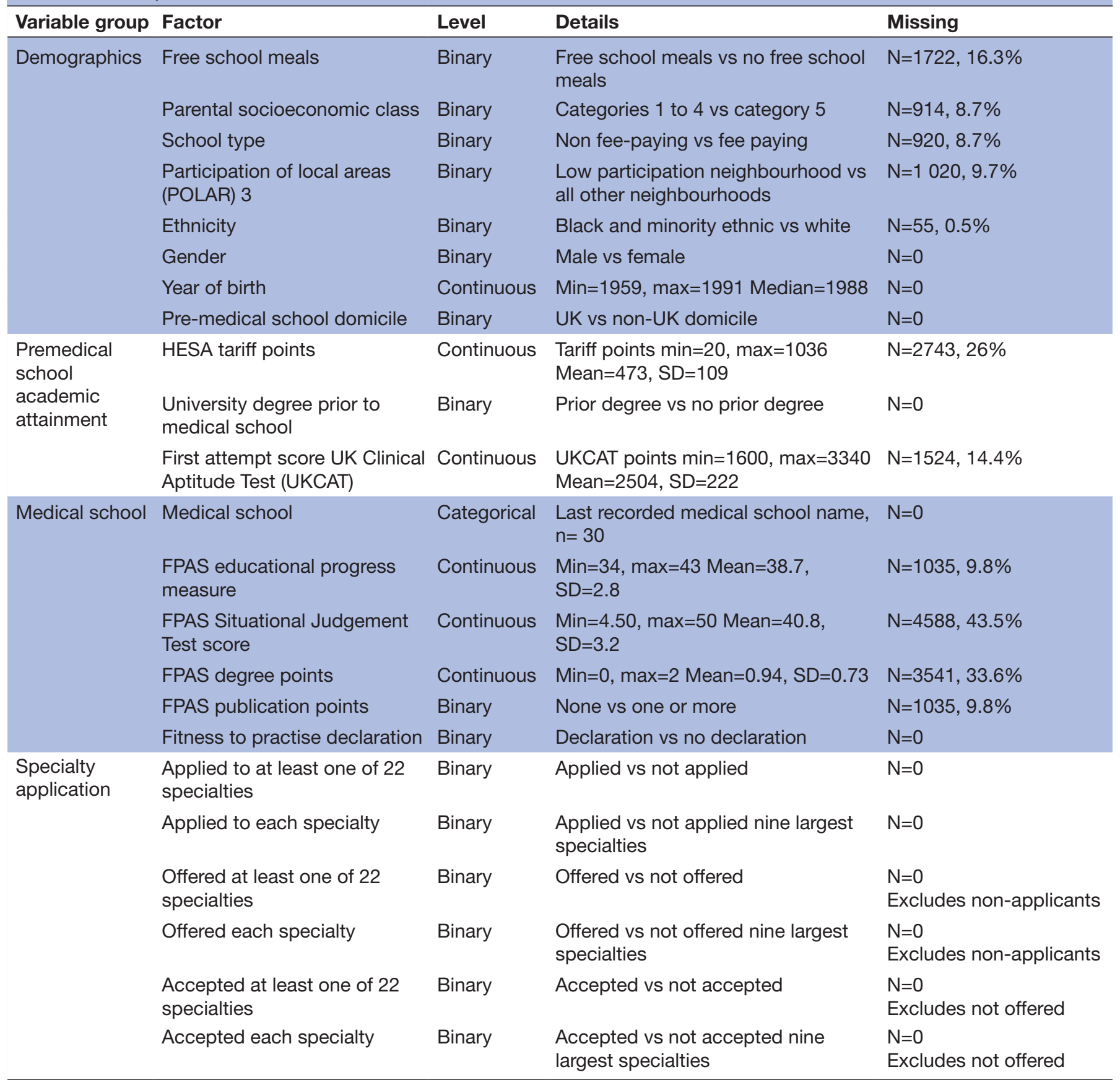

FPAS, Foundation Programme Application System; HESA, Higher Education Statistics Agency.

second class or upper second class; 2=additional undergraduate degree first class, Master's degree or doctorate). We also recoded publication points into a binary variable $(0=$ none, $1=$ one or more $)$.

We controlled for the medical school doctors graduated from since it is known that graduates of different medical schools differ significantly in terms of the specialties they apply to and their academic performance (eg, refs 25-27). We also controlled for ethnicity, socioeconomic status and premedical school country of domicile, since these are known to influence academic performance. ${ }^{28} 29$ Ethnicity was a binary variable (black and minority ethnic or BME vs white) created by collapsing all 'non-white' groups, including mixed, into the BME category and all white groups into the white category. We included four socioeconomic measures, each of which we collapsed into binary variables: socioeconomic class (SEC; based on parental occupation: higher managerial vs all others), school type (fee-paying vs non-fee-paying), participation of local areas (POLAR) 3 (low neighbourhood higher education participation vs all other; non-UK missing) and free school meals (no free school meals vs free school meals). We chose those variables because they measure slightly different things: POLAR3 is the only area level 
variable, SEC is a measure of parental occupation, school type is measure of the student's educational background (and students from poor backgrounds can receive scholarships to attend private schools) and free school meals is a marker of parental income.

\section{Statistical analysis}

Univariate tests (t-tests, Mann-Whitney tests, $\chi^{2}$ tests) were conducted in SPSS V.22. Multilevel binomial logistic regressions with a random effect of medical school and fixed effects of background variables were conducted using lme4 in R. We considered medical school a random effect because the medical schools are a sample of all medical schools in the world.

The multilevel models were fitted to predict applications, offers and acceptances overall and for each of the nine larger specialties that showed a univariate effect of sex on outcome. Predictor variables were sex, premedical school attainment (HESA tariff points. UKCAT score, GAMSAT score) and Foundation Programme Application Scores which were used as a measure of medical school attainment (EPM, SJT, degree points, publication points). The following confounders were also included in the models: ethnicity, year of birth, pre-medical school domicile, parental SEC, free school meals, school type, POLAR3, prior undergraduate degree and medical school FtP declaration.

For each regression model, missing values were multiply imputed for the following variables: UKCAT score, HESA tariff score, FPAS SJT scores, FPAS EPM scores, FPAS degree points, FPAS publication points and the four socioeconomic variables, using 25 iterations of the Multiple Imputation function in SPSS, with indicators being: regression model outcome (eg, whether applied for specialty training or not), birth year, gender, ethnicity, medical school, year entered medical school, HESA tariff score, UKCAT total score ( $\min =1600$, max 3360), GAMSAT total score, FPAS SJT score $(\min 0, \max =50)$, FPAS EPM score ( $\min =34$, $\max =43$ ), FPAS degree points, FPAS publication points. Imputed scores were used in the models.

\section{Patient involvement}

No patients were involved in this study.

\section{RESULTS}

Nearly three quarters of doctors $(7634 / 10559 ; 72.2 \%)$ had applied for specialty training. Of 22 specialties recorded, nine had 250+ applicants and 90+ acceptances: acute care common stem emergency medicine (ACCS EM), clinical radiology, core anaesthetics training, core medical training, core psychiatry training, core surgical training, GP, O\&G and paediatrics. One hundred and seventy-three doctors had only applied to smaller specialties and were excluded from the analyses on the larger specialties. 
Table 3 Mixed effects logistic regression of medical school (random effect), demographics, prior attainment and fitness to practise declaration (fixed effects) on the probability of applying to specialty training versus not applying ( $n=10559)$

\begin{tabular}{|c|c|c|c|c|c|c|}
\hline & Estimate & SE & OR & $\begin{array}{l}\text { Lower } \\
95 \% \mathrm{Cl}\end{array}$ & $\begin{array}{l}\text { Upper } \\
95 \% \mathrm{Cl}\end{array}$ & $P$ value \\
\hline Female & -0.0633 & 0.0477 & 0.9387 & 0.8549 & 1.0307 & 0.1847 \\
\hline HESA tariff ${ }^{\star *}$ & 0.0008 & 0.0003 & 1.0008 & 1.0003 & 1.0013 & 0.0009 \\
\hline UKCAT score** & -0.0003 & 0.0001 & 1.0008 & 1.0003 & 1.0013 & 0.0009 \\
\hline EPM score ${ }^{\star *}$ & 0.0495 & 0.0095 & 1.0508 & 1.0313 & 1.0705 & 0.0001 \\
\hline SJT score* & -0.0295 & 0.0096 & 0.9709 & 0.9528 & 0.9894 & 0.0021 \\
\hline Degree points ${ }^{\star \star}$ & -0.7255 & 0.0417 & 0.4841 & 0.4461 & 0.5253 & $<0.0001$ \\
\hline Publication points ${ }^{* *}$ & 0.3047 & 0.0573 & 1.3562 & 1.2122 & 1.5174 & $<0.0001$ \\
\hline UK domicile ${ }^{\star *}$ & 0.3104 & 0.0862 & 1.1610 & 0.9372 & 1.4382 & 0.0003 \\
\hline Graduate entry** & 0.7103 & 0.0785 & 2.0346 & 1.7445 & 2.3729 & $<0.0001$ \\
\hline Birth year** & -0.0750 & 0.0044 & 0.9278 & 0.9198 & 0.9358 & $<0.0001$ \\
\hline BME & -0.0056 & 0.0031 & 0.9944 & 0.9883 & 1.0004 & 0.0689 \\
\hline High SEC* & -0.1126 & 0.0561 & 0.8935 & 0.8005 & 0.9973 & 0.0446 \\
\hline Fee paying school & -0.0678 & 0.0538 & 0.9345 & 0.8410 & 1.0384 & 0.2078 \\
\hline No free school meals & 0.0412 & 0.0946 & 0.9597 & 0.7972 & 1.1552 & 0.6633 \\
\hline High local participation (POLAR)* & -0.2866 & 0.1284 & 0.7508 & 0.5838 & 0.9657 & 0.0256 \\
\hline FtP declaration* & -0.1715 & 0.0871 & 0.8424 & 0.7102 & 0.9992 & 0.0489 \\
\hline
\end{tabular}

The random effect of medical school was highly statistically significant $(p<0.0001)$.

Statistically significant fixed effects in bold: ${ }^{*} p<0.05 ;{ }^{* *} p<0.001$.

BME, black and minority ethnic; EPM, Educational Performance Measure; FtP, fitness to practise; HESA, Higher Education Statistics Agency;

POLAR, participation of local areas; SEC, socioeconomic class; SJT, Situational Judgement Tests; UKCAT, UK Clinical Aptitude Test.

\section{Univariate results}

Across all specialties, sex was not related to whether any application versus none was made $(\mathrm{p}=0.25)$, but women were more likely to get at least one offer versus none $(\mathrm{OR}=1.40 ; 95 \% \mathrm{CI}=1.25$ to $1.58 ; \mathrm{p}<0.001)$ and to accept an offer versus none $(\mathrm{OR}=1.54 ; 95 \% \mathrm{CI}=1.30$ to 1.84 ; $\mathrm{p}<0.001)$. There were significant sex differences in applications to seven of the nine largest specialties (women favouring GP, O\&G, paediatrics and men favouring ACCS EM, clinical radiology, core anaesthetics training and core surgical training), sex differences in offers to two (GP and paediatrics, both favouring women) and sex differences in acceptances to two (GP and ACCS EM, both with more women accepting). See table 2 for details. GP was the only specialty that showed a significant sex difference in applications (unadjusted OR $=1.51 ; 95 \%$ $\mathrm{CI}=1.37$ to $1.66 ; \mathrm{p}<0.001$ ), offers (unadjusted $\mathrm{OR}=1.42$; $95 \% \mathrm{CI}=1.21$ to $1.66 ; \mathrm{p}<0.001)$ and acceptances (unadjusted $\mathrm{OR}=1.34 ; 95 \% \mathrm{CI}=1.05$ to $1.70 ; \mathrm{p}=0.03$ ), with all favouring women.

There were various sex differences in prior attainment. At application to medical school, men in the sample had on average 36 more UKCAT points than women $(\mathrm{p}<0.001)$, but their HESA tariff points were not statistically different, and they were no more likely to have a degree at entry to medical school. At application to Foundation Training, women had higher EPM $(\mathrm{p}<0.001)$ and SJT scores $(p<0.001)$, whereas men had more publications $(\mathrm{p}=0.007)$ and degree points $(\mathrm{p}<0.001)$. Men were significantly more likely to have a FtP declaration $(\mathrm{OR}=2.12$; $95 \% \mathrm{CI}=1.82$ to $2.45 ; \mathrm{p}<0.001)$.

Doctors who had not applied for specialty training had lower HESA tariff points $(\mathrm{p}<0.001)$, UKCAT score $(p<0.001)$ and FPAS degree points $(p<0.001)$ than those who had. There was no difference in EPM $(\mathrm{p}=0.23)$ or SJT scores $(\mathrm{p}=0.13)$.

There were significant differences by medical school on all predictor variables, including the proportion of women (range: 44.7 to $67.0 ; \mathrm{p}<0.001$ ), average prior attainment (all measures significant at $\mathrm{p}<0.001$ ) and the proportion with an FtP declaration (range: $3.5 \%$ to $16.7 \% ; \mathrm{p}<0.001)$. Medical schools also differed in the proportion of their graduates who applied to specialty training (range: $62.5 \%$ to $87.4 \%$; $\mathrm{p}<0.001$ ), received an offer (range: $65.0 \%$ to $92.9 \%$; $\mathrm{p}<0.001$ ) and accepted an offer (range: $83.5 \%$ to $95.7 \%$; $p<0.001$ ). All the nine largest specialties except core anaesthetics, O\&G and paediatrics showed significant medical school differences in applications. By contrast, only core medical training, core surgical training and GP showed medical school differences in offers, and only ACCS EM, core surgical training and GP showed medical school differences in acceptances. Only GP and core surgical training showed medical school differences in applications, offers and acceptances. 
Table 4 Mixed effects logistic regression of medical school (random effect), demographics, prior attainment and fitness to practise declaration (fixed effects) on the probability of being offered a place on any specialty training programme or not $(n=7634)$

\begin{tabular}{|c|c|c|c|c|c|c|}
\hline & Estimate & SE & OR & $\begin{array}{l}\text { Lower } \\
95 \% \mathrm{Cl}\end{array}$ & $\begin{array}{l}\text { Upper } \\
95 \% \mathrm{Cl}\end{array}$ & $P$ value \\
\hline Female ${ }^{\star \star}$ & 0.2750 & 0.0627 & 1.3165 & 1.1643 & 1.4887 & $<0.0001$ \\
\hline HESA tariff* & 0.0010 & 0.0004 & 1.0010 & 1.0003 & 1.0017 & 0.00585 \\
\hline UKCAT score & -0.0001 & 0.0002 & 0.9999 & 0.9996 & 1.0003 & 0.74034 \\
\hline EPM score ${ }^{\star \star}$ & 0.1040 & 0.0131 & 1.1096 & 1.0815 & 1.1385 & $<0.0001$ \\
\hline SJT score & 0.0231 & 0.0141 & 1.0234 & 0.9955 & 1.0520 & 0.10185 \\
\hline Degree points ${ }^{\star \star}$ & 0.2890 & 0.0558 & 1.3351 & 1.1968 & 1.4894 & $<0.0001$ \\
\hline Publication points & 0.0457 & 0.0814 & 1.0468 & 0.8924 & 1.2278 & 0.57474 \\
\hline Non-UK domicile ${ }^{\star \star}$ & -0.4240 & 0.0948 & 0.6544 & 0.5435 & 0.7881 & $<0.0001$ \\
\hline Graduate entry* & -0.2070 & 0.0980 & 0.8130 & 0.6709 & 0.9852 & 0.03498 \\
\hline Birth year & -0.0027 & 0.0137 & 0.9973 & 0.9709 & 1.0244 & 0.84156 \\
\hline BME & 0.0005 & 0.0054 & 1.0005 & 0.9936 & 1.0093 & 0.7314 \\
\hline High SEC & 0.0563 & 0.0728 & 1.0579 & 0.9172 & 1.2202 & 0.4391 \\
\hline Fee paying school & -0.0520 & 0.0757 & 0.9493 & 0.8184 & 1.1012 & 0.4926 \\
\hline No free school meals & -0.0578 & 0.1200 & 0.9438 & 0.7460 & 1.1941 & 0.6289 \\
\hline High local participation (POLAR) & 0.1070 & 0.1510 & 1.1129 & 0.8278 & 1.4962 & 0.4806 \\
\hline FtP declaration & -0.0471 & 0.1141 & 0.9540 & 0.7927 & 1.2394 & 0.9383 \\
\hline
\end{tabular}

The random effect of medical school was highly statistically significant $(p<0.0001)$.

Statistically significant fixed effects in bold: ${ }^{*} \mathrm{p}<0.05 ;{ }^{* *} \mathrm{p}<0.001$.

BME, black and minority ethnic; EPM, Educational Performance Measure; FtP, fitness to practise; HESA, Higher Education Statistics Agency;

POLAR, participation of local areas; SEC, socioeconomic class; SJT, Situational Judgement Tests; UKCAT, UK Clinical Aptitude Test.

\section{Multivariate results}

Sex differences in applications remained in the same seven specialties with similar magnitudes after controlling for medical school attended, prior attainment and demographics. The only specialties showing sex differences in offers were GP and Paediatrics, both favouring women. In the fully adjusted models, the only specialty to show sex differences beyond offers was GP, women being more likely to apply (odds $=1.51 ; 95 \% \mathrm{CI}=1.37$ to $1.67 ; \mathrm{p}<0.001$ ), to be offered a place (odds=1.29; 95\% CI $=1.03$ to 1.11; $\mathrm{p}=0.004$ ) and to accept an offer (odds $=1.34 ; 95 \%$ $\mathrm{CI}=1.05$ to $1.70 ; \mathrm{p}<0.05)$ to GP training. See table 2 .

Doctors with a medical school FtP declaration were slightly less likely to apply to specialty training overall $(\mathrm{OR}=0.84 ; 95 \% \mathrm{CI}=0.71$ to $1.00 ; \mathrm{p}=0.048)$. Of those who did apply, having an FtP declaration was a small predictor of applying to ACCS Emergency Medicine (odds=1.39; $95 \% \mathrm{CI}=1.01$ to $1.92 ; \mathrm{p}=0.046)$. Of those who received an offer to any specialty, those with an FtP declaration were slightly less likely to accept (odds $=0.71 ; 95 \% \mathrm{CI}=0.52$ to $0.98 ; \mathrm{p}=0.036$ ), after adjusting for all other factors. It is important to bear in mind in interpreting these findings that we performed a large number of tests, with analyses done for all specialties and then repeated for each of nine specialties separately, increasing the probability of getting a statistically significant result by chance alone (ie, increasing the chance of type I error). Significant independent predictors of applying, being offered a place and accepting a place on any specialty are shown in tables 3-5.

\section{DISCUSSION}

There were significant sex differences in the specialty applications of this sample of 10559 UK medical graduates. Women were more likely to apply to GP, O\&G and paediatrics, and men were more likely to apply to core surgical training, ACCS EM and clinical radiology. Women were more likely to receive an offer versus none, and to receive an offer in GP and paediatrics specifically. Women were more likely to accept an offer if they received one, and to accept an offer in GP specifically. Sex differences largely remained after controlling for prior academic attainment and having a FtP declaration, as well as medical school attended and other demographics. In the fully adjusted models, GP was the only specialty with significant sex differences at all three stages: applications, offers and acceptances; women being more likely to apply and to accept an offer, and also being more likely to be offered a place. Having an FtP declaration was a small predictor of not applying to specialty training, and of rejecting an offer across all specialties, although the large number of tests performed increases the possibility that this was due to type I error. 
Table 5 Mixed effects logistic regression of medical school (random effect), demographics, prior attainment and fitness to practise declaration (fixed effects) on the probability of accepting an offer to specialty training or not $(n=6208)$

\begin{tabular}{|c|c|c|c|c|c|c|}
\hline & Estimate & SE & OR & $\begin{array}{l}\text { Lower } \\
95 \% \mathrm{Cl}\end{array}$ & $\begin{array}{l}\text { Upper } \\
95 \% \mathrm{CI}\end{array}$ & $P$ value \\
\hline Female $^{\star \star}$ & 0.3868 & 0.0935 & 1.4723 & 1.2259 & 1.7682 & $<0.0001$ \\
\hline HESA tariff & -0.0004 & 0.0005 & 0.9996 & 0.9987 & 1.0005 & 0.3316 \\
\hline UKCAT score & -0.0001 & 0.0002 & 0.9999 & 0.9994 & 1.0003 & 0.5447 \\
\hline EPM score & 0.0476 & 0.0189 & 1.0487 & 1.0106 & 1.0883 & 0.0117 \\
\hline SJT score & -0.0264 & 0.0194 & 0.9740 & 0.9377 & 1.0117 & 0.1739 \\
\hline Degree points ${ }^{\star \star}$ & -0.4350 & 0.0798 & 0.6472 & 0.5535 & 0.7569 & $<0.0001$ \\
\hline Publication points* & -0.2472 & 0.1068 & 0.7810 & 0.6335 & 0.9628 & 0.0206 \\
\hline Non-UK domicile* & -0.3161 & 0.1451 & 0.7290 & 0.5486 & 0.9687 & 0.0293 \\
\hline Graduate entry & 0.2617 & 0.1433 & 1.2991 & 0.9810 & 1.7204 & 0.0678 \\
\hline Birth year** & -0.0344 & 0.0007 & 0.9662 & 0.9649 & 0.9675 & $<0.0001$ \\
\hline BME & 0.0115 & 0.0095 & 1.0116 & 0.9930 & 1.0306 & 0.2244 \\
\hline High SEC & -0.1424 & 0.1141 & 0.8673 & 0.6934 & 1.0846 & 0.2120 \\
\hline Fee paying school & -0.1802 & 0.1067 & 0.8351 & 0.6775 & 1.0294 & 0.0913 \\
\hline No free school meals & 0.1407 & 0.1771 & 1.1511 & 0.8135 & 1.6287 & 0.4270 \\
\hline High local participation (POLAR) & 0.0170 & 0.2402 & 1.0172 & 0.6352 & 1.6288 & 0.9436 \\
\hline FtP declaration* & -0.3379 & 0.1608 & 0.7133 & 0.5205 & 0.9775 & 0.0356 \\
\hline
\end{tabular}

Statistically significant fixed effects in bold: ${ }^{*} p<0.05 ;{ }^{* *} p<0.001$. The effect of medical school was statistically significant at $p<0.007$. BME, black and minority ethnic; EPM, Educational Performance Measure; FtP, fitness to practise; HESA, Higher Education Statistics Agency; POLAR, participation of local areas; SEC, socioeconomic class; SJT, Situational Judgement Tests; UKCAT, UK Clinical Aptitude Test.

The raw sex differences in applications are consistent with previous research from the UK and other countries. ${ }^{2} 3152630$ Our finding that women were more likely than men to get an offer in GP selection, but not in selection for core surgical training reflects Davison and colleagues' analysis of national data ${ }^{12}$ but differs from Thomas and colleagues' analysis of a smaller subsample. ${ }^{11}$ To our knowledge this is the first study to assess sex differences in the likelihood of receiving and accepting an offer to specialty training after controlling for prior attainment, as well as controlling for medical school, other demographics and a measure of medical school professionalism. It is also the first that we know of to assess whether FtP issues at medical school predict specialty preferences and selection outcomes.

A considerable strength of the study is the large sample size (three quarters of all entrants to medical school from 2007 to 2008) and the longitudinal nature of the data, obtained from the UKMED. This made it possible to examine recruitment to nine different specialties in the UK. It also meant we could conduct multivariate analyses to understand whether sex segregation in some specialties is due to sex differences on the potential confounder of academic attainment, both prior to and during medical school. Because UKMED data are collected by the GMC as part of their statutory duty to regulate medical education in the UK, we did not have to rely on voluntary completion of surveys for data, unlike previous analyses. ${ }^{11}$
The study has some methodological weaknesses. We did not consider multiple applications or acceptances from multiple offers. Seventy per cent of doctors in our sample applied to one specialty only, and this did not differ by sex $(p=0.77)$; however, it is likely that the number of multiple applications varies by specialty. For example, a previous study using the same dataset but looking only at GP applicants found that only 59\% (vs 70\%) made a single specialty training application; however, women were more likely to apply to GP after controlling for prior attainment and other demographics regardless of whether they had applied to multiple specialties or not. ${ }^{26}$ We also did not formally compare sex differences between specialties taking into account competition ratios, and we only analysed data from first applications. Since women were more likely to receive and accept and offer first time around, it is possible that men are more likely to apply a second time around, which may then influence the final proportions of men and women in different specialties. We combined applications across years, which meant we could not account for the possibility that different selection processes occurred during different application cycles. We did not look at potential interactions, for example between age and sex, or medical school and sex, which have been shown in other studies to influence specialty choice. ${ }^{2531}$ Using administrative data rather than data collected for research purposes limited our ability to infer reasons for the sex differences observed. There were 
also considerable amounts of missing data on some variables, in particular because some of the cohorts within the sample had not taken a test, with multiple imputation used to avoid excluding large amounts of data. Our dataset was truncated because we could only include graduates who were eligible to apply to specialty training by 2015 . The study findings are not generalisable outside of the UK.

This study suggests that sex differences in specialty applications and outcomes are driven largely by factors unmeasured in this study, and not by academic, other demographic or medical school differences. In terms of differential applications, previous research has shown that these factors are likely to include how 'plannable', technical and people-oriented a specialty is, ${ }^{2}$ the career prospects a specialty offers, a trainee's domestic circumstances and their perceptions of their own ability and interests. ${ }^{32}$ There is also evidence that, while some specialties such as surgery and paediatrics show sex differences very early in medical school training, ${ }^{33}$ experiences during medical school and postgraduate training can influence specialty choices. ${ }^{12} 34$ This suggests that efforts to reduce sex segregation should focus on understanding and addressing medical career choice early on, as well as on understanding whether men and women have different experiences during training, and on removing any perceived or real barriers to career progression and enjoyment within sex-segregated specialties.

It is unclear why women were more likely to receive an offer, and to accept an offer compared with men. The sex differences in GP were the most striking of any of the nine largest specialties, and this itself requires more research to understand. It is important to note that sex differences in applications and acceptances are the result of doctors' choices, which themselves are underpinned by sociological and educational factors; whereas sex differences in offers reflect the specialty selection processes. GP selection comprises written and face-to-face assessments, and potential sex differences on those assessments were not taken into account in our analysis of offers. Performance in GP selection has been found to predict subsequent performance in the Membership of the Royal College of General Practitioners exit examinations, ${ }^{35}$ in which women outperform men. ${ }^{36}{ }^{37}$ As such, the relationship between sex differences in offers and sex differences within GP training also merits further exploration.

\section{CONCLUSIONS}

Sex differences in specialty applications, offers and acceptances result from factors other than prior academic attainment, medical school FtP declarations, medical school and other demographics. GP was the only specialty with significant sex differences in applications, offers and acceptances: women were more likely to apply; of those who applied, women were more likely to be offered a place; and of those offered a place, women were more likely to accept. Further research exploring the reasons underlying sex differences in applications and acceptances, as well as the differences in offers within GP and paediatrics, is important for future work place planning and equity.

Acknowledgements The UK Medical Education Database (UKMED) UKMEDP20 provided the data via an extract generated on $01 / 08 / 2016$, and it was approved for publication by the UKMED Advisory Board on 25/09/2017. We are grateful to UKMED for the use of these data; however UKMED bears no responsibility for our analysis or interpretation. The data includes information derived from that collected by the Higher Education Statistics Agency Limited (HESA) and provided to the General Medical Council (GMC). Source: HESA Student Record 2007/2008 and 2008/2009 Copyright Higher Education Statistics Agency Limited. The Higher Education Statistics Agency Limited makes no warranty as to the accuracy of the HESA Data, and cannot accept responsibility for any inferences or conclusions derived by third parties from data or other information supplied by it. We thank Daniel Smith from GMC for his advice on our application for data and support with data linkage.

Contributors KK, CV and EU conceived of the study and EU wrote the first draft of the original protocol. KK, CV, HP, KW and HJ designed the data analysis, with $\mathrm{KW}$ and $\mathrm{HJ}$ conducting the data analysis. KW wrote the first draft of the report. All authors read and approved the final version of the article. KW is the article guarantor.

Funding The authors have not declared a specific grant for this research from any funding agency in the public, commercial or not-for-profit sectors.

Competing interests KW reports grants, personal fees and non-financial support from General Medical Council, personal fees and non-financial support from Membership of the Royal Colleges of Physicians (UK), personal fees from University of Dundee School of Medicine, non-financial support from UK Medical Education Database, other from Higher Education Funding Council England, non-financial support from Medical Schools Council, grants from National Institute for Health Research, outside the submitted work. CV reports non-financial support from Actelion, outside the submitted work. HP reports grants from General Medical Council, outside the submitted work. EU reports non-financial support from the General Medical Council and financial support from University College London outside the submitted work.

Patient consent for publication Not required.

Ethics approval The UK Medical Schools Council agreed that all approved applications for research projects using data exclusively held by UKMED would meet the criteria for a blanket exemption from the need to apply for ethics approval that would be recognised by ethics committees relevant to the UK medical schools. Queen Mary University of London Research Ethics Committee, on behalf of all UK medical schools, confirms ethics exemption, noting that NHS review is not required and that only de-identified data accessed under safe haven conditions is used.

Provenance and peer review Not commissioned; externally peer reviewed.

Data sharing statement Data files used in the study are securely held by the UK Medical Education Database and cannot be shared by the authors, but are available via application (see www.ukmed.ac.uk).

Open access This is an open access article distributed in accordance with the Creative Commons Attribution Non Commercial (CC BY-NC 4.0) license, which permits others to distribute, remix, adapt, build upon this work non-commercially, and license their derivative works on different terms, provided the original work is properly cited, appropriate credit is given, any changes made indicated, and the use is non-commercial. See: http://creativecommons.org/licenses/by-nc/4.0/.

\section{REFERENCES}

1. Lambert EM, Holmboe ES. The relationship between specialty choice and gender of U.S. medical students, 1990-2003. Acad Med 2005;80:797-802.

2. Elston M. Women and medicine: the future. London: Royal College of Physicians, 2009.

3. Buddeberg-Fischer B, Klaghofer R, Abel T, et al. Swiss residents' speciality choices-impact of gender, personality traits, career motivation and life goals. BMC Health Serv Res 2006;6:137.

4. McManus IC, Sproston KA. Women in hospital medicine in the United Kingdom: glass ceiling, preference, prejudice or cohort effect? J Epidemiol Community Health 2000;54:10-16. 
5. Mc K. When Does Gender Matter?:Gender Differences in Specialty Choice Among Physicians. Work and Occupations 2011;38:221-62.

6. Rodriguez Santana I, Chalkley M. Getting the right balance? A mixed logit analysis of the relationship between UK training doctors' characteristics and their specialties using the 2013 National Training Survey. BMJ Open 2017;7:e015219.

7. Scanlan GM, Cleland J, Johnston $\mathrm{P}$, et al. What factors are critical to attracting NHS foundation doctors into specialty or core training? A discrete choice experiment. BMJ Open 2018;8:e019911.

8. Buddeberg-Fischer B, Stamm M, Buddeberg C, et al. The impact of gender and parenthood on physicians' careers-professional and personal situation seven years after graduation. BMC Health Serv Res 2010;10:40.

9. Patterson F, Ashworth V, Zibarras L, et al. Evaluations of situational judgement tests to assess non-academic attributes in selection. Med Educ 2012;46:850-68.

10. MacKenzie RK, Dowell J, Ayansina D, et al. Do personality traits assessed on medical school admission predict exit performance? A UK-wide longitudinal cohort study. Adv Health Sci Educ Theory Pract 2017;22:365-85.

11. Thomas H, Davison I, Gee H, et al. The fairness, effectiveness and acceptability of selection for specialty training in the UK. Br J Hosp Med 2013;74:47-51.

12. Davison I, McManus IC, Taylor C. Evaluation of GP Specialty Selection, 2016.

13. Scrimgeour DSG, Cleland J, Lee AJ, et al. Impact of performance in a mandatory postgraduate surgical examination on selection into specialty training. BJS Open 2017;1:67-74.

14. Canadian Resident Matching Service. CARMS. 2018 https://www. carms.ca/en/data-and-reports/r-1/r-1-match-reports-2017/.

15. Colquitt WL, Smith IP, Killian CD. Specialty selection and success in obtaining choice of residency training among 1987 U.S. medical graduates by race-ethnicity and gender. Acad Med 1992;67:660-71.

16. Hewett L, Lewis M, Collins H, et al. Gender Bias in Diagnostic Radiology Resident Selection, Does it Exist? Acad Radiol 2016;23:101-7.

17. de Oliveira GS, Akikwala T, Kendall MC, et al. Factors affecting admission to anesthesiology residency in the United States: choosing the future of our specialty. Anesthesiology 2012;117:243-51.

18. Unwin E, Woolf $\mathrm{K}$, Wadlow $\mathrm{C}$, et al. Sex differences in medico-legal action against doctors: a systematic review and meta-analysis. BMC Med 2015;13:172.

19. Paton LW, Tiffin PA, Smith D, et al. Predictors of fitness to practise declarations in UK medical undergraduates. BMC Med Educ 2018;18:68.

20. Santen SA, Petrusa E, Gruppen LD. The relationship between promotions committees' identification of problem medical students and subsequent state medical board actions. Adv Health Sci Educ Theory Pract 2015;20:421-30.

21. Yates J, James D. Risk factors at medical school for subsequent professional misconduct: multicentre retrospective case-control study. BMJ 2010;340:c2040.
22. Papadakis MA, Hodgson CS, Teherani A, et al. Unprofessional behavior in medical school is associated with subsequent disciplinary action by a state medical board. Acad Med 2004;79:244-9.

23. Unwin $\mathrm{E}$, Woolf $\mathrm{K}$, Wadlow $\mathrm{C}$, et al. Disciplined doctors: does the sex of a doctor matter? A cross-sectional study examining the association between a doctor's sex and receiving sanctions against their medical registration. BMJ Open 2014;4:e005405.

24. UKMED Data Dictionary, 2018.

25. Twigg V, Aldridge K, McNally SA, et al. Does choice of medical school affect a student's likelihood of becoming a surgeon? The Bulletin of the Royal College of Surgeons of England 2018;100:90-5.

26. Gale TCE, Lambe PJ, Roberts MJ. Factors associated with junior doctors' decisions to apply for general practice training programmes in the UK: secondary analysis of data from the UKMED project. BMC Med 2017;15:220.

27. McManus IC, Elder AT, de Champlain A, et al. Graduates of different UK medical schools show substantial differences in performance on MRCP(UK) Part 1, Part 2 and PACES examinations. BMC Med 2008;6:5.

28. Woolf K, Potts HW, McManus IC. Ethnicity and academic performance in UK trained doctors and medical students: systematic review and meta-analysis. BMJ 2011;342:d901.

29. Kumwenda B, Cleland JA, Walker K, et al. The relationship between school type and academic performance at medical school: a national, multi-cohort study. BMJ Open 2017;7:e016291.

30. Baerlocher MO, Walker M. Does gender impact upon application rejection rate among Canadian radiology residency applicants? Can Assoc Radiol J 2005;56:232-7.

31. Lambert TW, Smith F, Goldacre MJ. Career specialty choices of UK medical graduates of 2015 compared with earlier cohorts: questionnaire surveys. Postgrad Med J 2018;94:191-7.

32. Lambert T, Goldacre R, Smith F, et al. Reasons why doctors choose or reject careers in general practice: national surveys. Br J Gen Pract 2012;62:e851-8.

33. Cleland J, Johnston PW, French FH, et al. Associations between medical school and career preferences in Year 1 medical students in Scotland. Med Educ 2012;46:473-84.

34. Woolf K, Elton C, Newport M. The specialty choices of graduates from Brighton and Sussex Medical School: a longitudinal cohort study. BMC Med Educ 2015;15:46.

35. Patterson F, Lievens F, Kerrin M, et al. The predictive validity of selection for entry into postgraduate training in general practice: evidence from three longitudinal studies. Br J Gen Pract 2013;63:e734-41.

36. Esmail A, Roberts C. Academic performance of ethnic minority candidates and discrimination in the MRCGP examinations between 2010 and 2012: analysis of data. BMJ 2013;347:f5662.

37. Siriwardena AN, Irish B, Asghar ZB, et al. Comparing performance among male and female candidates in sex-specific clinical knowledge in the MRCGP. Br J Gen Pract 2012;62:e446-50. 